\title{
Article \\ Unidirectional Alignment of Surface-Grafted ZnO Nanorods in Micrometer-Thick Cells Using Low-Molecular-Weight Liquid Crystals
}

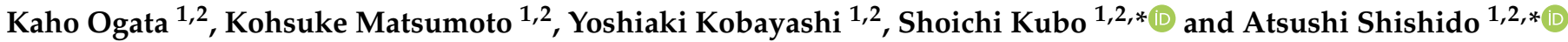 \\ 1 Laboratory for Chemistry and Life Science, Institute of Innovative Research, Tokyo Institute of Technology, \\ R1-12, 4259 Nagatsuta, Midori-ku, Yokohama 226-8503, Japan; kogata-st@polymer.res.titech.ac.jp (K.O.); \\ kmatsumoto-st@polymer.res.titech.ac.jp (K.M.); ykobayashi-st@polymer.res.titech.ac.jp (Y.K.) \\ 2 Department of Chemical Science and Engineering, School of Materials and Chemical Technology, \\ Tokyo Institute of Technology, 2-12-1 Ookayama, Meguro-ku, Tokyo 152-8552, Japan \\ * Correspondence: kubo@res.titech.ac.jp (S.K.); ashishid@res.titech.ac.jp (A.S.)
}

check for

updates

Citation: Ogata, K.; Matsumoto, K.;

Kobayashi, Y.; Kubo, S.; Shishido, A. Unidirectional Alignment of Surface-Grafted ZnO Nanorods in Micrometer-Thick Cells Using Low-Molecular-Weight Liquid Crystals. Molecules 2022, 27, 689. https://doi.org/10.3390/ molecules27030689

Academic Editor: Haifeng Yu

Received: 29 December 2021

Accepted: 18 January 2022

Published: 21 January 2022

Publisher's Note: MDPI stays neutral with regard to jurisdictional claims in published maps and institutional affiliations.

Copyright: (C) 2022 by the authors. Licensee MDPI, Basel, Switzerland. This article is an open access article distributed under the terms and conditions of the Creative Commons Attribution (CC BY) license (https:// creativecommons.org/licenses/by/ $4.0 /)$.

\begin{abstract}
Inorganic nanomaterials such as nanotubes and nanorods have attracted great attention due to their anisotropic properties. Although the alignment control of inorganic nanomaterials is key to the development of functional devices utilizing their fascinating properties, there is still difficulty in achieving uniform alignment over a large area with a micrometer thickness. To overcome this problem, we focused on liquid crystals (LCs) to promote the alignment of anisotropic nanomaterials, taking advantage of the cooperative motion of LCs. We present the uniform, one-dimensional alignment of $\mathrm{ZnO}$ nanorods along the direction of LCs in micrometer-thick cells by grafting nematic LC polymers from the nanorod surfaces to provide miscibility with the host LCs. Polarized optical microscopy and polarized UV-visible absorption spectroscopy revealed the unidirectional alignment of nematic LC polymer-grafted $\mathrm{ZnO}$ nanorods parallel to the nematic host LCs.
\end{abstract}

Keywords: nanorod; alignment; liquid crystal; surface modification

\section{Introduction}

Inorganic anisotropic nanomaterials such as nanotubes and nanorods have attracted great attention due to their remarkable properties derived from their size effects and anisotropic shapes, such as electrical conductivity [1,2], optical properties of polarized emission and absorption [3,4], and thermal conductivity [5,6]. Various devices have been proposed as promising applications for nanomaterials-for example, piezoelectric energy harvesting [7,8], photovoltaics [9-11], and photonics [12]. To fully utilize their fascinating properties in functional devices, it is essential to control the alignment of nanomaterials at device-relevant length scales. To date, various alignment methods have been reported. For example, vertically aligned nanorods on substrates have been fabricated by metal organic chemical vapor deposition [13,14], pulsed laser deposition [15], hydrothermal growth [16], chemical bath deposition [17], surfactant-assisted sol-gel processes [18], and dopant mediated assembly [19]. All these methods are applicable to substrates satisfying the condition of the controlled growth of materials. Alternatively, methods for aligning presynthesized nanorods could expand the versatility of nanorod materials. Electric/magnetic fields [20-22], mechanical forces [23], and selective incorporation into microphase-separated block copolymers [24-26] have been used to induce the alignment of nanorods. However, there still remain challenges in unidirectional alignment over a large area, mostly due to aggregation.

Liquid crystals (LCs), which have both fluidity and anisotropy, are candidate materials for promoting nanorod alignment. Nanorods surface-modified with thermotropic LC molecules have been proposed for the utilization of anisotropic properties with regulated 
structures [27-30]. The formation of lyotropic LCs from nanorods modified with block copolymers has also been shown to utilize LC properties [31-33]. These studies suggest that the control of interactions between nanorods and LCs is key to their alignment. In order to further enhance the interaction between nanorods and LCs and effectively induce uniform alignment, we carefully regulated the surface density of LC polymers modified in inorganic nanorods and achieved the unidirectional alignment of zinc oxide $(\mathrm{ZnO})$ nanorods over a large area [34]. Our concept of the surface-density regulation of LCs in nanorods allows cooperative molecular interactions with the surrounding low-molecular-weight host LC molecules, leading to hierarchical, uniform alignment without the aggregation of nanorods. However, the control of the alignment in the thickness direction is limited to only a few tens of nanometers near to the alignment layer. If the alignment of nanorods can be controlled to the thickness of micrometers, their applications as functional anisotropic materials will be greatly expanded by utilizing the nanoscale anisotropic properties on a macroscopic scale.

In this study, we report the alignment behavior of the LC polymer-grafted $\mathrm{ZnO}$ nanorods in an LC cell with a thickness of approximately $5 \mu \mathrm{m}$. Low-molecular-weight LCs with a high fluidity and the ability of molecular alignment are adopted as host LCs to drive the nanorods surface-grafted with LC polymers. We evaluate the miscibility of the surface-modified nanorods to the host LCs, which is the key to inducing the cooperative motion. Finally, we investigate the optical properties of the surface-modified nanorods in the host LCs in $5 \mu \mathrm{m}$-thick cells and demonstrate their unidirectional alignment in homogeneous and homeotropic manners.

\section{Results and Discussion}

\subsection{Liquid Crystalline Behavior of the Nematic LC Host Dispersed with LC Polymer-Grafted Nanorods}

We anticipated the alignment of nanorods by the cooperative interaction of host LCs and nematic LC polymer grafted from nanorod surfaces. Here, we adopted 4-cyano-4'pentylbiphenyl, $5 \mathrm{CB}$, as a low-molecular-weight host $\mathrm{LC}$ to induce the alignment of $\mathrm{ZnO}$ nanorods grafted with the nematic LC polymer, poly\{4-[4-(4-methoxyphenyloxycarbonyl) phenoxy]butyl methacrylate\}, PMA(4OPB), as shown in Figure 1. Firstly, the LC behavior of PMA(4OPB)-grafted $\mathrm{ZnO}$ nanorods dispersed in $5 \mathrm{CB}$ was investigated by differential scanning calorimetry (DSC) to evaluate their miscibility. Figure 2 shows the DSC thermograms of $\mathrm{PMA}(4 \mathrm{OPB})$-grafted nanorods, $5 \mathrm{CB}$, and their 1:20 mixture in weight ratio. PMA(4OPB)-grafted nanorods showed an endothermic peak at $98^{\circ} \mathrm{C}$ during the heating process and an exothermic peak at $97^{\circ} \mathrm{C}$ during the cooling process (Figure 2a). Compared with the previous report [34], these peaks were attributable to the nematic to isotropic phase transition of the grafted PMA $(4 \mathrm{OPB})$. The nematic to isotropic phase transition enthalpies $\left(\Delta H_{\mathrm{N}-\mathrm{I}}\right)$, expressed as total energy per molar quantity of LC mesogens, were 0.59 and $0.56 \mathrm{~kJ} / \mathrm{mol}$ for the heating and cooling processes, respectively. $5 \mathrm{CB}$ showed a broad exothermic peak at around $-15^{\circ} \mathrm{C}$ derived from recrystallization, endothermic peaks corresponding to the melting at $24{ }^{\circ} \mathrm{C}$, and the nematic to isotropic phase transition at $35^{\circ} \mathrm{C}$ during the heating process, while the exothermic peaks of the isotropic to nematic phase transition were at $35^{\circ} \mathrm{C}$ and the crystallization was at $-18{ }^{\circ} \mathrm{C}$ during the cooling process (Figure $2 \mathrm{~b}$ ). Both $\Delta H_{\mathrm{N}-\mathrm{I}}$ values were $0.51 \mathrm{~kJ} / \mathrm{mol}$ during the heating and cooling processes, respectively.

In the case of their mixture (Figure 2c), the peaks due to the nematic to isotropic phase transition of PMA(4OPB)-grafted nanorods at $98^{\circ} \mathrm{C}$ (heating) and $97^{\circ} \mathrm{C}$ (cooling) disappeared. Instead, endothermic and exothermic peaks during the heating and cooling processes were observed at $35^{\circ} \mathrm{C}$, which was identical to the nematic to isotropic phase transition of $5 \mathrm{CB}$. The melting point during the heating process was observed at $17^{\circ} \mathrm{C}$, but no crystallization peak was observed due to supercooling. Polarized optical microscope $(\mathrm{POM})$ images of the mixture under crossed polarizers exhibited schlieren textures, which is characteristic of a nematic phase, at a temperature below $35^{\circ} \mathrm{C}$ and became dark at higher temperatures (Figure 3). According to the DSC and POM measurements, the peaks of the 
DSC thermogram at $35^{\circ} \mathrm{C}$ were attributable to the nematic to isotropic phase transition. The $\Delta H_{\mathrm{N}-\mathrm{I}}$ values of the mixture were 0.33 and $0.39 \mathrm{~kJ} / \mathrm{mol}$ in the heating and cooling processes, respectively. The decrease in the phase transition enthalpies compared to 5CB suggested that the added PMA(4OPB)-grafted nanorods locally disordered the molecular orientation. Nevertheless, the single phase transition by DSC and the optically anisotropic textures, without significant segregation by POM, confirmed that PMA(4OPB)-grafted nanorods are miscible with a 5 CB host and form a uniform nematic phase.

\section{Host LC}

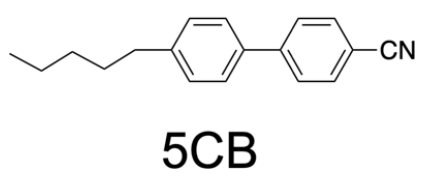

\section{Surface-modified ZnO nanorod}

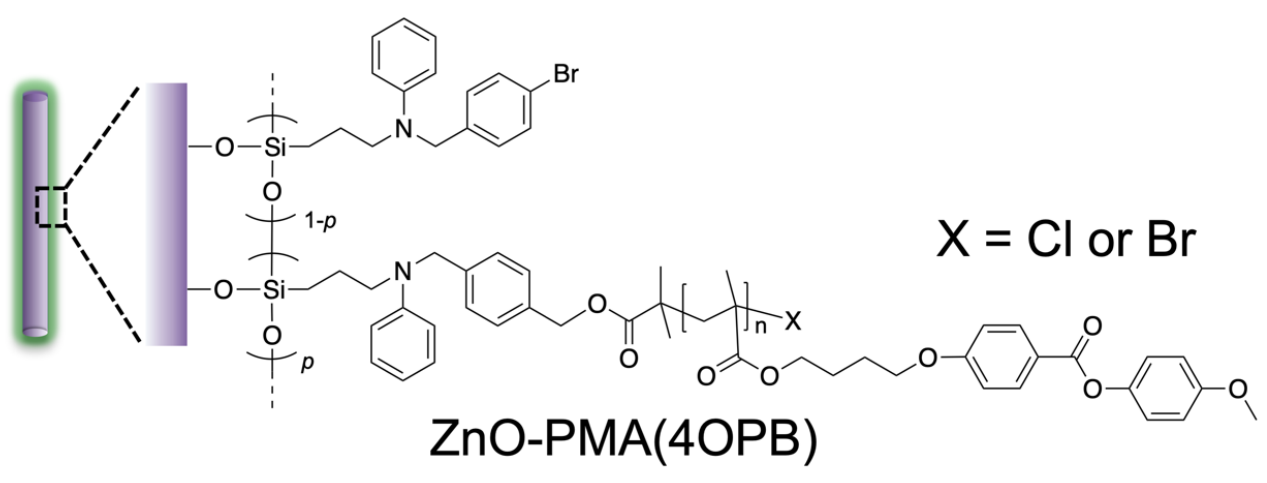

Figure 1. Chemical structures used in this study.

\subsection{Homogeneous Alignment of $\mathrm{ZnO}$ Nanorods in Host LC}

The alignment behavior of PMA(4OPB)-grafted $\mathrm{ZnO}$ nanorods dispersed with a $5 \mathrm{CB}$ host was firstly investigated in an approximately $5 \mu \mathrm{m}$-thick cell coated with a homogeneous alignment layer which had been obtained by a rubbing treatment. Figure 4 shows the optical properties of the sample cell filled with the mixture. Similarly, in the 5CB cell (Figure A1a), the obtained cell was optically transparent, as shown in Figure 4a. The POM observation of the cell under crossed polarizers showed a clear contrast for every $45^{\circ}$ rotation and the image became completely dark when the polarization direction was parallel or perpendicular to the rubbing direction, as indicated in the top images of Figure $4 \mathrm{~b}$. The molecular alignment direction was confirmed by the POM observation with a tint plate (retardation $(R)=137 \mathrm{~nm}$ ). As shown in the bottom images of Figure $4 \mathrm{~b}$, the additive and subtractive color effects were found when the optical axis of the tint plate was parallel and perpendicular to the rubbing direction, respectively. The POM results indicated that the mesogens of the host LC were aligned parallel to the rubbing direction. The value of $R$ for the mixture, measured using a Berek compensator, was $840 \mathrm{~nm}$. Using the relation of $R=d \Delta n$, where $\mathrm{d}$ is the cell thickness $(d=5 \mu \mathrm{m})$ and $\Delta n$ is birefringence, the value of $\Delta n$ was calculated to be 0.16 . Similarly, $\Delta n$ of 5 CB was determined to be 0.15 (Figure A1b). The almost identical $\Delta n$ values, regardless of the existence of nanorods, suggested that PMA(4OPB)-grafted nanorods are well miscible with the host 5CB and form homogeneous alignment cooperatively without a significant disturbance of the molecular alignment. 


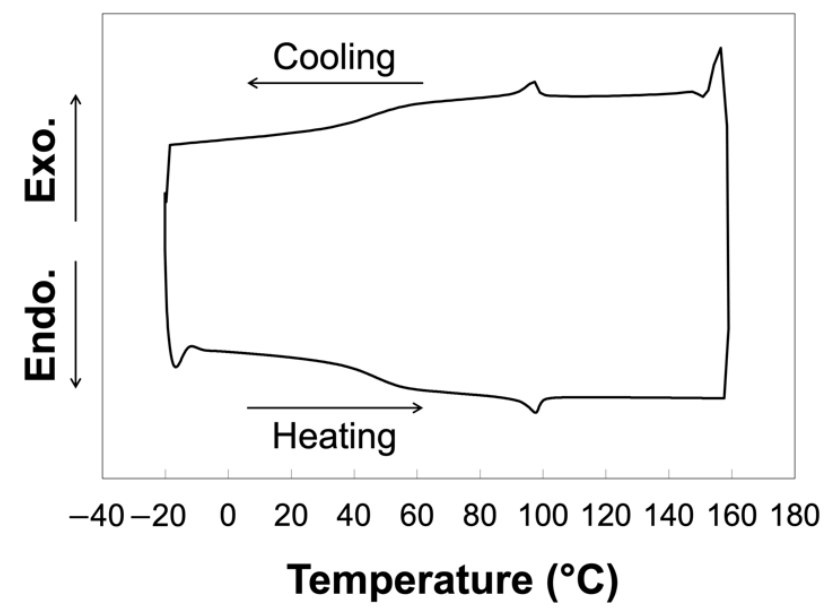

(a)

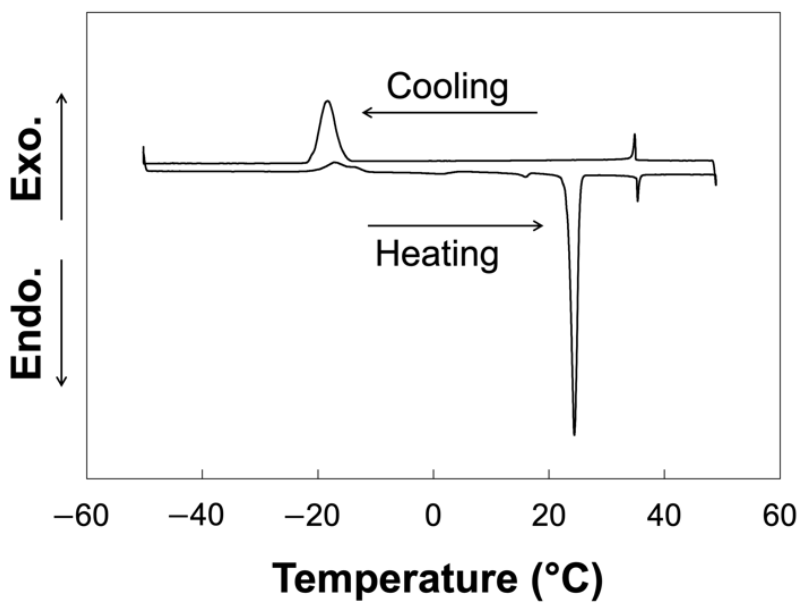

(b)

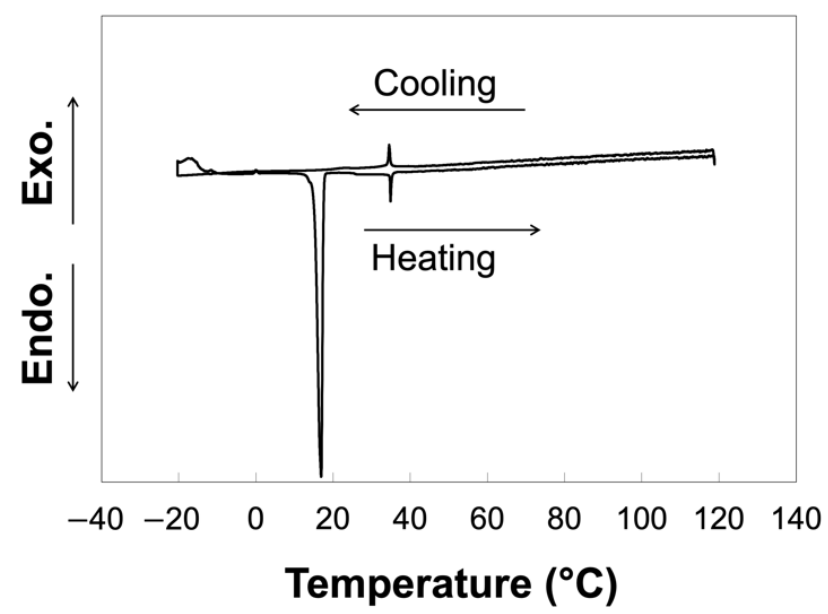

(c)

Figure 2. Differential scanning calorimetry (DSC) thermograms at 3rd heating and cooling cycle: (a) PMA(4OPB)-grafted $\mathrm{ZnO}$ nanorods; (b) 5CB; (c) their mixture. Scanning rate: $10{ }^{\circ} \mathrm{C} / \mathrm{min}$ (a) and $1^{\circ} \mathrm{C} / \min (\mathbf{b}, \mathbf{c})$. 

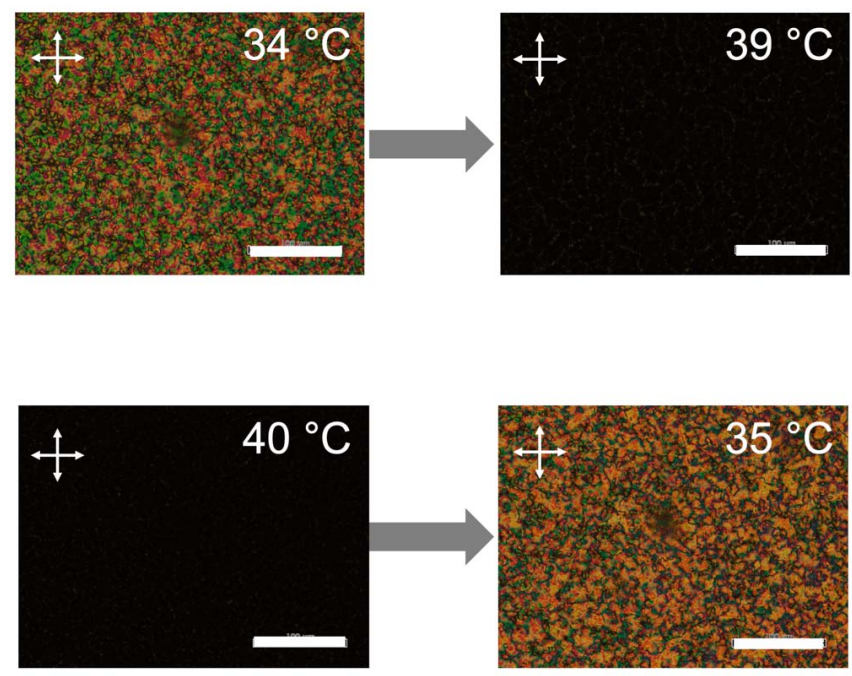

Figure 3. Polarized optical microscope (POM) images of the mixture of PMA(4OPB)-grafted $\mathrm{ZnO}$ nanorods and 5CB under crossed polarizers at the heating process (top) and cooling process (bottom). Scale bars, $100 \mu \mathrm{m}$. White crossed arrows show the direction of the polarizers.

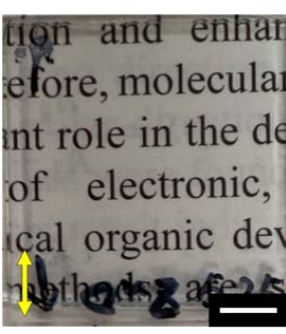

(a)
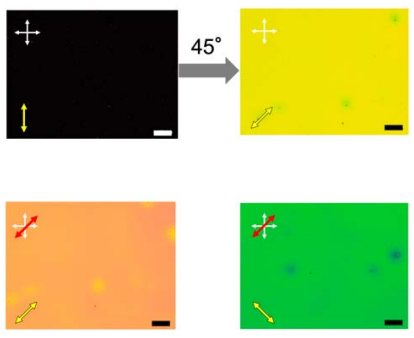

(b)

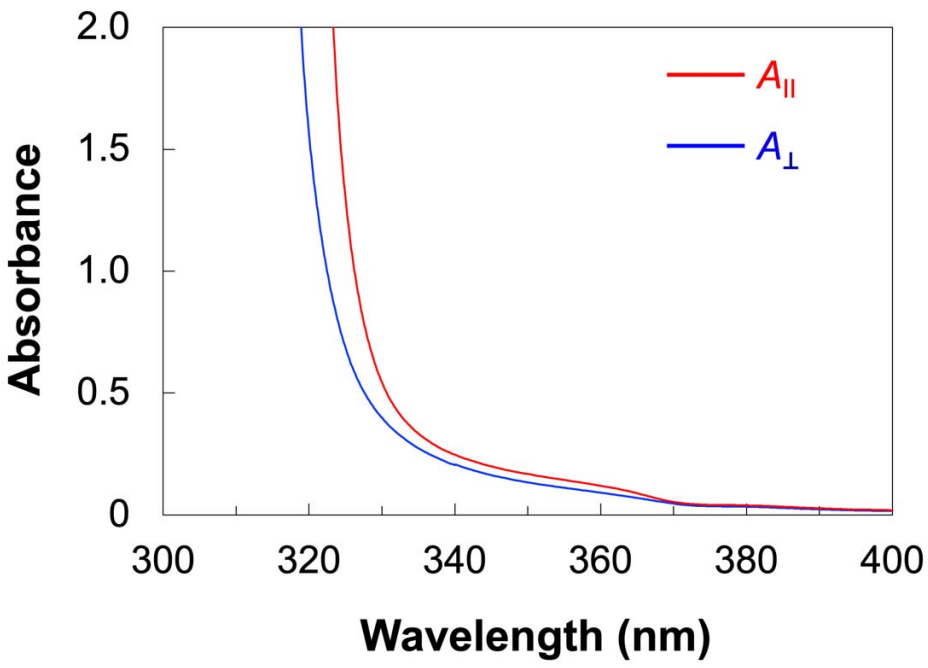

(c)

Figure 4. Optical properties of 5CB doped with PMA(4OPB)-grafted $\mathrm{ZnO}$ nanorods with a weight ratio of 20:1 in a glass cell with a homogeneous alignment layer. (a) Photograph. Scale bar, $5 \mathrm{~mm}$. (b) POM images under crossed polarizers without (top) and with (bottom) a tint plate with a retardation of $137 \mathrm{~nm}$. White crossed arrows show the direction of the polarizers. Yellow arrows show the rubbing direction. Red arrows show the direction of the tint plate. Scale bars, $200 \mu \mathrm{m}$. (c) Polarized UV-vis absorption spectra. $A_{\|}$and $A_{\perp}$ are absorbances parallel and perpendicular to the rubbing direction. 
To further investigate the alignment of $\mathrm{ZnO}$ nanorods as well as mesogens, we measured the polarized ultraviolet (UV)-visible (vis) absorption spectra (Figure 4c). We defined the absorbances parallel $\left(A_{\|}\right)$and perpendicular $\left(A_{\perp}\right)$ to the rubbing direction, respectively. The absorption below $340 \mathrm{~nm}$ was derived from the cyanobiphenyl moieties of the host $5 C B$. The absorption band at around $350 \mathrm{~nm}$, which was not observed for 5CB (Figure A1c), was assigned to the $\mathrm{ZnO}$ nanorods. The absorbance parallel to the rubbing direction was larger compared to the perpendicular direction for both bands. The order parameter $(S)$, which showed the degree of the in-plane alignment, was calculated by using the following equation [35]:

$$
S=\frac{A_{\|}-A_{\perp}}{A_{\|}+2 A_{\perp}}
$$

The $S$ value for $\mathrm{ZnO}$ nanorods was 0.09 at $355-360 \mathrm{~nm}$. The $S$ value for the host LC mesogens is not discussed here because the absorption of $\mathrm{ZnO}$ nanorods is also overlapped with that of mesogens. The results of POM and polarized UV-vis absorption spectra indicated that the $\mathrm{ZnO}$ nanorods were aligned cooperatively with the host LCs according to the rubbed alignment layer in micrometer-thick cells.

\subsection{Homeotropic Alignment of $\mathrm{ZnO}$ Nanorods in the Host LC}

The $\mathrm{ZnO}$ nanorod-dispersed LC in a glass cell with a homeotropic alignment layer showed different optical properties from that in the homogeneously aligned cell, as shown in Figure 5. The glass cell was optically transparent, as shown in Figure 5a. A conoscopic POM image exhibited a clear isogyre (Figure 5b). The result indicated that host 5CB molecules in the cell have a homeotropic alignment. In addition, the alignment directions of both the host LC and PMA(4OPB)-grafted $\mathrm{ZnO}$ nanorods were evaluated by polarized UV-vis absorption spectroscopy. We determined the absorbances parallel $\left(A_{\mathrm{H}}\right)$ and perpendicular $\left(A_{\mathrm{V}}\right)$ to the direction of the sample injection, respectively. As shown in Figure $5 \mathrm{c}$, the absorbance derived from $\mathrm{ZnO}$ and mesogens was identical regardless of the polarization direction. These results show that PMA(4OPB)-grafted $\mathrm{ZnO}$ nanorods are homeotropically aligned with host LCs in a micrometer-thick cell.

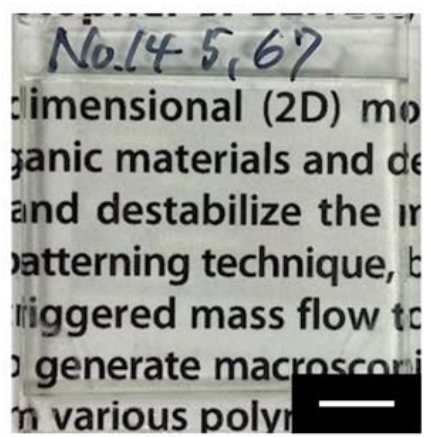

(a)

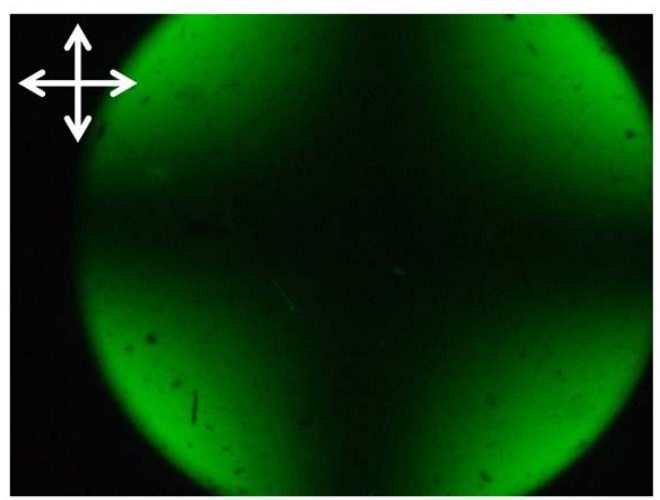

(b)

Figure 5. Cont. 


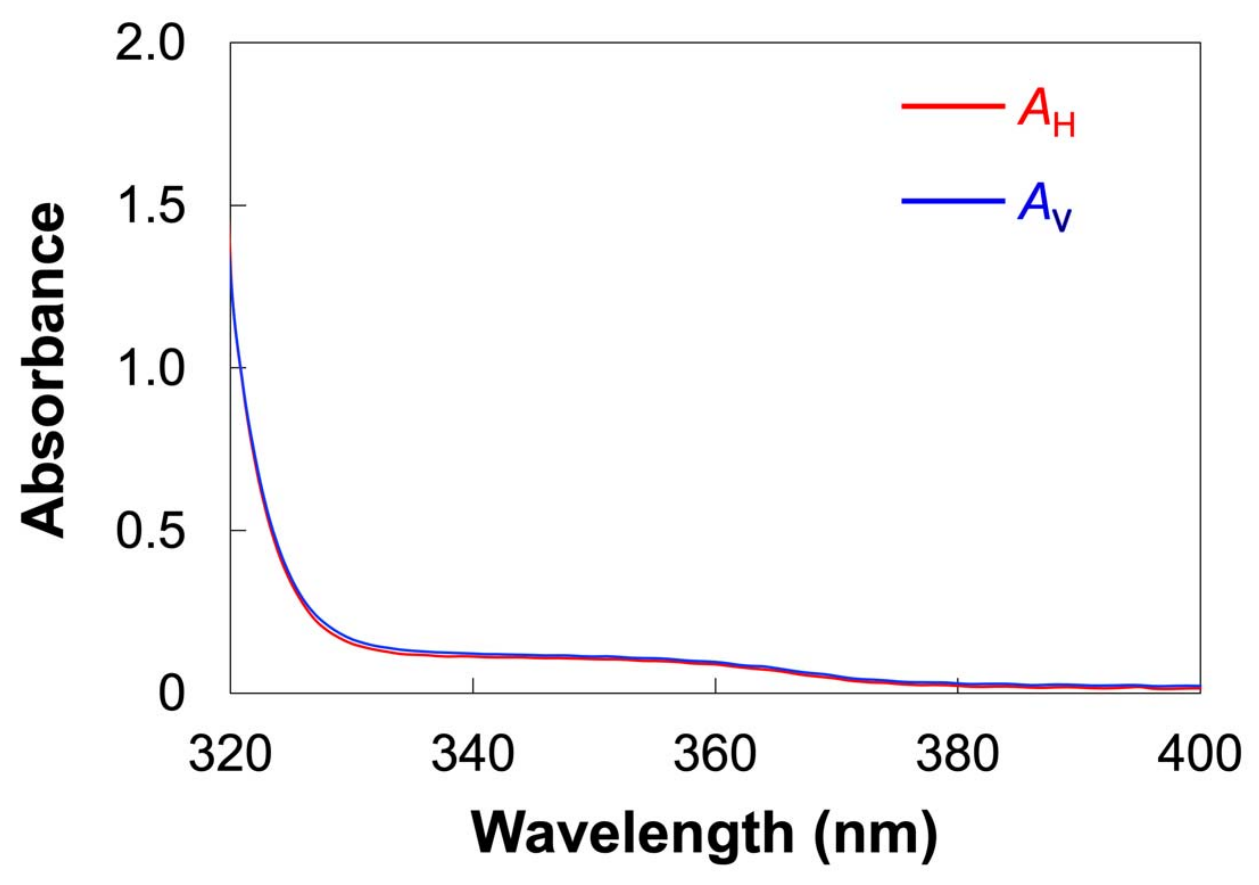

(c)

Figure 5. Optical properties of 5CB doped with PMA(4OPB)-grafted $\mathrm{ZnO}$ nanorods with a weight ratio of 20:1 in a glass cell with a homeotropic alignment layer. (a) Photograph. Scale bar, $5 \mathrm{~mm}$. (b) Conoscopic POM image. White crossed arrows show the direction of the polarizers. Scale bar, $200 \mu \mathrm{m}$. (c) Polarized UV-vis absorption spectra. $A_{\mathrm{H}}$ and $A_{\mathrm{V}}$ are the absorbances parallel and perpendicular to the injection direction of the sample.

\section{Materials and Methods}

\subsection{Materials}

A host LC (5CB) was provided by Merck, Darmstadt, Germany, and used without further purification. ZnO nanorods grafted with a nematic LC polymer PMA(4OPB) were synthesized as previously reported [34]. $\mathrm{ZnO}$ nanorods with an average diameter of $7 \mathrm{~nm}$ and a length of $50 \mathrm{~nm}$ were modified with initiator moieties for atom transfer radical polymerization (ATRP). The surface density of the ATRP initiator moieties was controlled to be $0.79 \mathrm{~nm}^{-2}$, which was determined by X-ray fluorescence (XRF) analysis. A nematic LC polymer PMA(4OPB) was grafted from the initiator-modified $\mathrm{ZnO}$ nanorods by ATRP with a feed molar ratio of 4-[4-(4-methoxyphenyloxycarbonyl)phenoxy]butyl methacrylate to the initiator moieties equal to 100. The monomer conversion measured by ${ }^{1} \mathrm{H}$ NMR was 33\%. The resultant PMA(4OPB)-grafted $\mathrm{ZnO}$ nanorods were observed using a transmission electron microscope (TEM), as shown in Figure 6. The precursor solution of the homogeneous alignment layer (AL1254) was supplied by JSR Corporation, Tokyo, Japan, and that for the homeotropic alignment layer (Sunever) was supplied by Nissan Chemical Corporation, Tokyo, Japan.

\subsection{Sample Preparation}

Glass cells with homogeneous and homeotropic alignment layers were fabricated according to the procedure shown in Figure 7. Glass substrates $(25 \mathrm{~mm} \times 15 \mathrm{~mm})$ were ultrasonically cleaned with 2-propanol for $30 \mathrm{~min}$ and treated with a UV-ozone cleaner (NLUV42, Nippon Laser \& Electronics Lab Co. Ltd., Nagoya, Japan) for $10 \mathrm{~min}$. The precursor solutions for the alignment layers were spincoated on the cleaned glass substrates and heated at $220^{\circ} \mathrm{C}$ for $1 \mathrm{~h}$. The glass substrates with the homogenous alignment layer were rubbed by a rubbing machine (MRG-100, EHC Co., Ltd., Hachioji, Japan). Glass cells were fabricated by adhering a pair of alignment layer-coated glass substrates with 
glue containing $5 \mu \mathrm{m}$-thick silica spacers (Thermo Scientific, 9000 Series, \#9005, Thermo Fisher Scientific, Waltham, MA, USA). The actual thickness of the prepared glass cells was determined by UV-vis spectroscopy based on the Fabry-Perot method. A typical transmission spectrum is shown in Figure 8. The thickness $(d)$ was calculated using the wavelengths of the interference maximum $\left(\lambda_{1}, \lambda_{2}\right)$ by the following equation [36]:

$$
d=\frac{\lambda_{1} \lambda_{2}}{2\left(\lambda_{1}-\lambda_{2}\right)}
$$

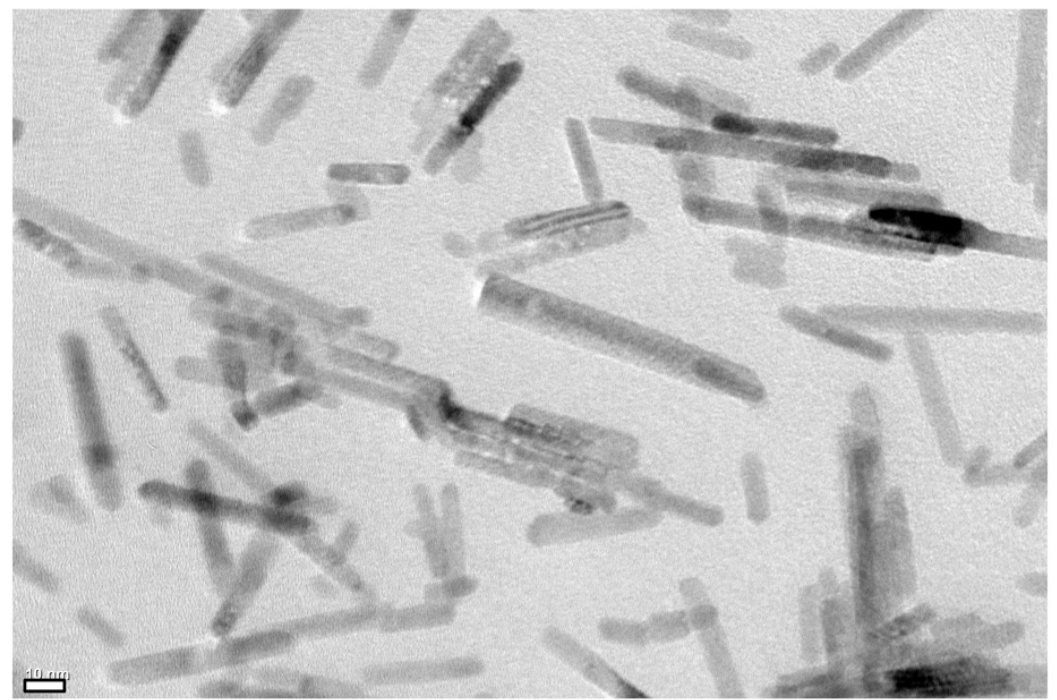

Figure 6. TEM image of the synthesized PMA(4OPB)-grafted $\mathrm{ZnO}$ nanorods. Scale bar, $10 \mathrm{~nm}$.

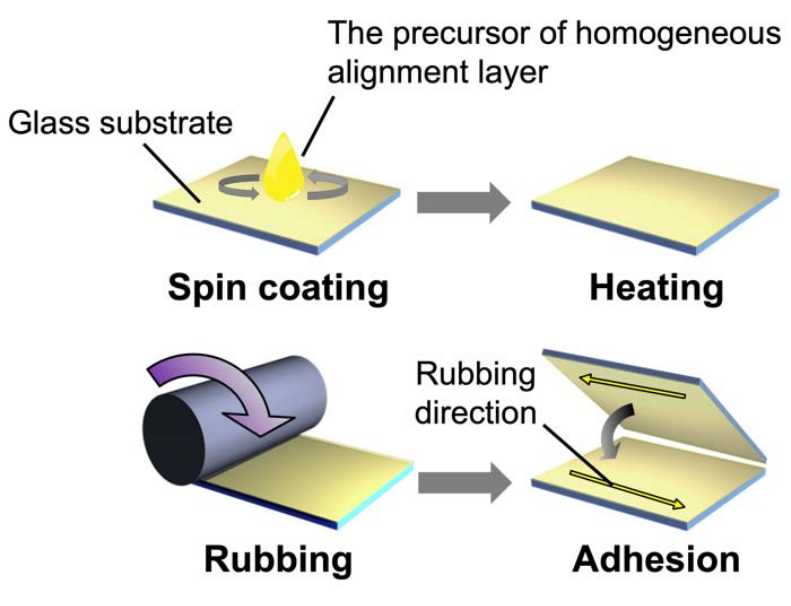

(a)

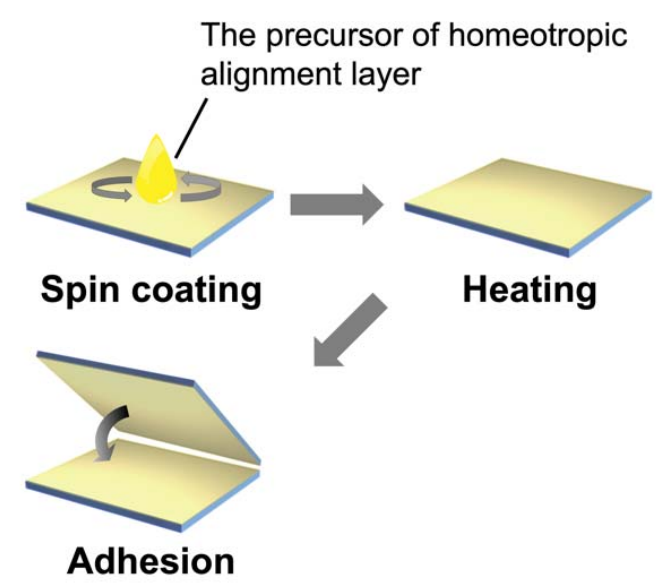

(b)

Figure 7. Schematic illustrations of the preparation of glass cells with homogeneous (a) and homeotropic (b) alignment layers.

The mixture of PMA(4OPB)-grafted $\mathrm{ZnO}$ nanorods and $5 \mathrm{CB}$ with a weight ratio of 1:20 was dispersed in tetrahydrofuran (THF) and stirred for $1 \mathrm{~h}$ at room temperature. After the removal of THF under vacuum for $6 \mathrm{~h}$, the mixture was further treated with an ultrasonicator (VS-02RD, Velvo-Clear, Tokyo, Japan) for $30 \mathrm{~min}$ at room temperature to improve the dispersity of PMA(4OPB)-grafted $\mathrm{ZnO}$ nanorods in the host 5CB. The sample mixture was injected into the hand-made glass cells by capillary action at $75^{\circ} \mathrm{C}$ and cooled down to $25^{\circ} \mathrm{C}$ at a rate of $10^{\circ} \mathrm{C} / \mathrm{min}$, as shown in Figure 9 . 


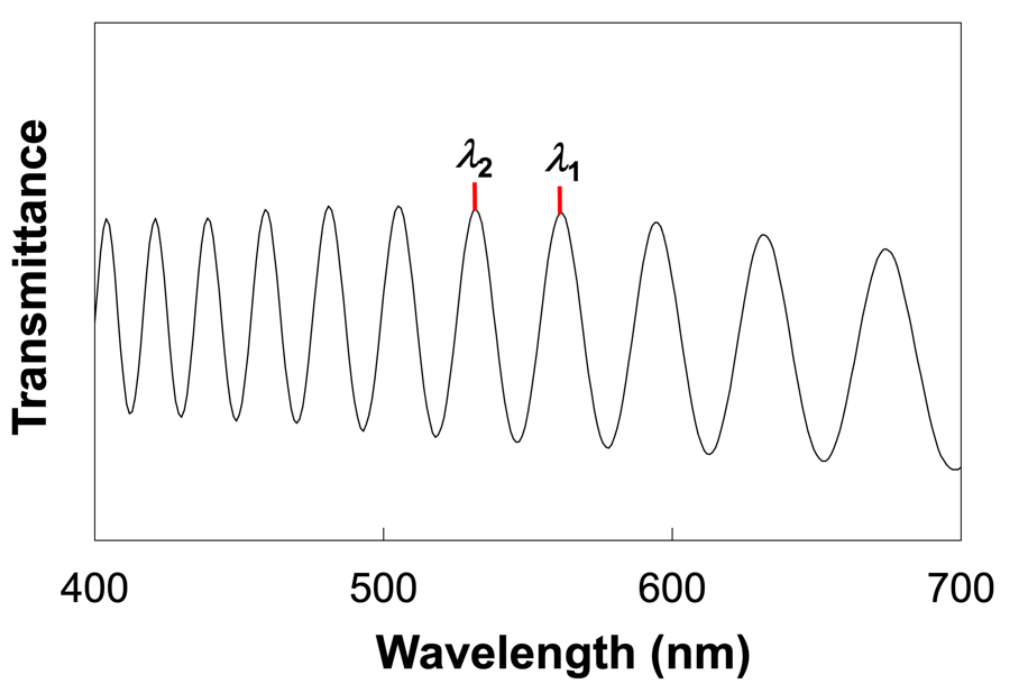

Figure 8. Typical transmission spectrum of the fabricated cell. $\lambda_{1}$ and $\lambda_{2}$ : peak wavelength.

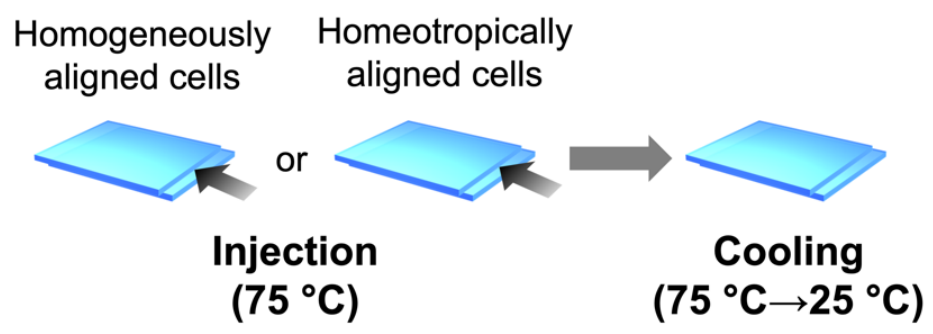

Figure 9. Schematic illustration of the injection of LCs into the glass cells.

\subsection{Characterization Equipment}

Differential scanning calorimetry (DSC) was performed using an Exstar DSC7000X differential scanning calorimeter (Hitachi High-Tech Corp., Tokyo, Japan). Polarized optical microscope (POM) images were obtained by a BX 50 polarized optical microscope (Olympus Corp., Tokyo, Japan) equipped with a hot stage (HS82, Mettler Toledo, Greifensee, Switzerland) and a tint plate (U-TP137, Olympus Corp., Tokyo, Japan) or a Berek compensator (U-CBE, Olympus Corp., Tokyo, Japan). Polarized UV-vis absorption spectra were measured by a UV-vis absorption spectrophotometer (V-670, JASCO Corp., Hachioji, Japan). XRF analysis was performed using an X-ray fluorescence spectrometer (ZSX Primus II, Rigaku Corp., Akishima, Japan). ${ }^{1} \mathrm{H}$ NMR spectra were recorded by an NMR spectrometer (Avance III, $400 \mathrm{MHz}$, Bruker Biospin, Bruker, Billerica, MA, USA). Transmission electron microscopy was performed with a JEM-2100 microscope (JEOL Ltd., Akishima, Japan).

\section{Conclusions}

In this study, we investigated the alignment control of nematic LC polymer-grafted nanorods dispersed in host LCs in micrometer-thick cells. The surface-grafted nanorods were well miscible with the host LCs and formed a uniform LC phase, as confirmed by DSC analysis. POM and polarized UV-visible absorption spectroscopy revealed the homogeneous and homeotropic alignment of the surface-grafted nanorods parallel to the host LCs in $5 \mu \mathrm{m}$-thick cells treated with alignment layers. Furthermore, the birefringence of the host LCs dispersed with surface-grafted nanorods was almost identical to that of $5 \mathrm{CB}$, which suggests a cooperative interaction of grafted nematic LC polymers with host LCs without significant segregation. The results reported herein will contribute to the development of various microscale devices by enabling us to effectively utilize the anisotropic properties of well-aligned nanomaterials. 
Author Contributions: Conceptualization, S.K. and A.S.; methodology, K.O., K.M. and Y.K.; investigation, K.O. and K.M.; visualization, K.O., K.M., Y.K.; writing-original draft preparation, K.O.; writing-review and editing, S.K. and A.S. All authors have read and agreed to the published version of the manuscript.

Funding: This research was supported by a Grant-in-Aid for Scientific Research on Innovative Areas "Molecular Engine" (JSPS KAKENHI Grant Number JP18H05422) and JST CREST Grant Number JPMJCR1814. This work was performed under the Cooperative Research Program of "Network Joint Research Center for Materials and Devices". This work was performed under the Research Program of "Dynamic Alliance for Open Innovation Bridging Human, Environment and Materials" in "Network Joint Research Center for Materials and Devices".

Data Availability Statement: The authors confirm that the data supporting the findings of this study are available within the article.

Acknowledgments: The authors are grateful to T. Fukushima and Y. Shoji (Tokyo Institute of Technology) for their assistance in synthesizing ATRP initiator moieties. The authors are also grateful to K. Kanie (Tohoku University) for his assistance in the XRF analysis. The authors are also grateful to Carlos Mejia for his help with the English editing of the manuscript.

Conflicts of Interest: The authors declare no conflict of interest.

Sample Availability: Samples of the compounds are not available from the authors.

\section{Appendix A}

A homogeneous alignment cell of $5 \mathrm{CB}$ was prepared for comparison. The optical properties are shown in Figure A1.

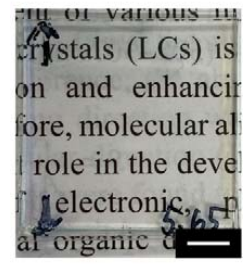

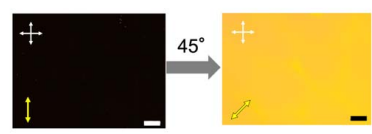

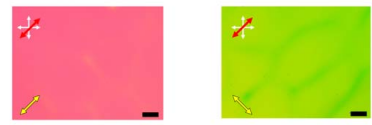

(b)

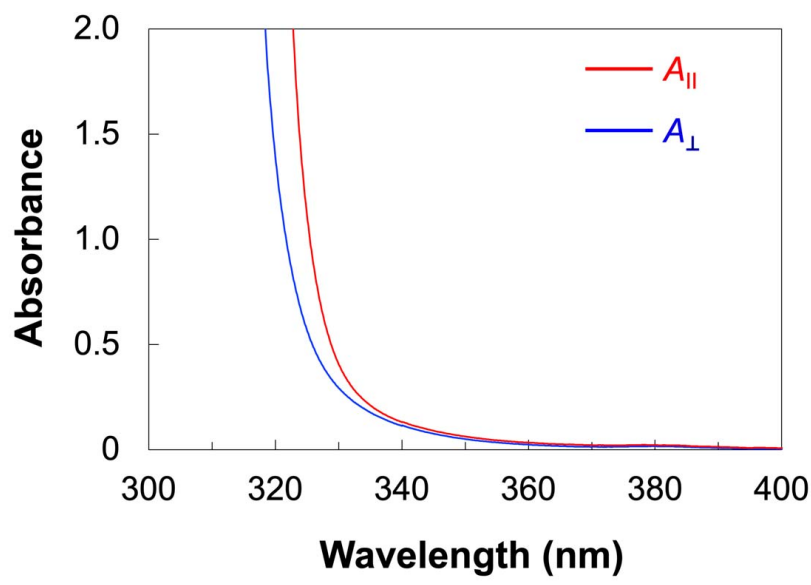

(c)

Figure A1. Optical properties of 5CB in a glass cell with a homogeneous alignment layer. (a) Photograph. Scale bar, $5 \mathrm{~mm}$. (b) POM images under crossed polarizers without (top) and with (bottom) a tint plate with a retardation of $137 \mathrm{~nm}$. White crossed arrows show the direction of the polarizers. Yellow arrows show the rubbing direction. Red arrows show the direction of the tint plate. Scale bars, $200 \mu \mathrm{m}$. (c) Polarized UV-vis absorption spectra. $A_{\|}$and $A_{\perp}$ are the absorbances parallel and perpendicular to the rubbing direction. 


\section{References}

1. Dayal, S.; Reese, M.O.; Ferguson, A.J.; Ginley, D.S.; Rumbles, C.; Kopidakis, N. The effect of nanoparticle shape on the photocarrier dynamics and photovoltaic device performance of poly(3-hexylthiophene): CdSe nanoparticle bulk heterojunction solar cells. Adv. Funct. Mater. 2010, 20, 2629-2635. [CrossRef]

2. Liu, J.; Wang, S.; Bian, Z.; Shan, M.; Huang, C. Organic/inorganic hybrid solar cells with vertically oriented ZnO nanowires. Appl. Phys. Lett. 2009, 94, 173107. [CrossRef]

3. Schneider, J.; Zhang, W.; Srivastava, A.K.; Chigrinov, V.G.; Kwok, H.S.; Rogach, A.L. Photoinduced micropattern alignment of semiconductor nanorods with polarized emission in a liquid crystal polymer matrix. Nano Lett. 2017, 17, 3133-3138. [CrossRef]

4. Cunningham, P.D.; Souza, J.B.; Fedin, I.; She, C.; Lee, B.; Talapin, D.V. Assessment of anisotropic semiconductor nanorod and nanoplatelet heterostructures with polarized emission for liquid crystal display technology. ACS Nano 2016, 10, 5769-5781. [CrossRef]

5. Huang, H.; Liu, C.; Wu, Y.; Fan, S. Aligned carbon nanotube composite films for thermal management. Adv. Mater. 2005, 17, 1652-1656. [CrossRef]

6. Das, R.; Alonso, J.; Porshokouh, Z.N.; Kalappattil, V.; Torres, D.; Phan, M.H.; Garaio, E.; García, J.Á.; Llamazares, J.L.S.; Srikanth, H. Tunable high aspect ratio iron oxide nanorods for enhanced hyperthermia. J. Phys. Chem. C 2016, 120, 10086-10093. [CrossRef]

7. Lee, M.; Chen, C.Y.; Wang, S.; Cha, S.N.; Park, Y.J.; Kim, J.M.; Chou, L.J.; Wang, Z.L. A hybrid piezoelectric structure for wearable nanogenerators. Adv. Mater. 2012, 24, 1759-1764. [CrossRef] [PubMed]

8. Qi, Y.; McAlpine, M.C. Nanotechnology-enabled flexible and biocompatible energy harvesting. Energy Environ. Sci. 2010, 3, 1275-1285. [CrossRef]

9. Ta, N.; Liu, J.Y.; Shen, W.J. Tuning the shape of ceria nanomaterials for catalytic applications. Chin. J. Catal. 2013, 34, 838-850. [CrossRef]

10. Beek, W.J.E.; Wienk, M.M.; Janssen, R.A.J. Efficient hybrid solar cells from zinc oxide nanoparticles and a conjugated polymer. Adv. Mater. 2004, 16, 1009-1013. [CrossRef]

11. Whittaker-Brooks, L.; McClain, W.E.; Schwartz, J.; Loo, Y.L. Donor-acceptor interfacial interactions dominate device performance in hybrid P3HT-ZnO nanowire-array solar cells. Adv. Energy Mater. 2014, 4, 1400585. [CrossRef]

12. Casse, B.D.F.; Lu, W.T.; Huang, Y.J.; Gultepe, E.; Menon, L.; Sridhar, S. Super-resolution imaging using a three-dimensional metamaterials nanolens. Appl. Phys. Lett. 2010, 96, 023114. [CrossRef]

13. Sun, M.; Zhang, Q.F.; Sun, H.; Zhang, J.; Wu, J.L. Enhanced ultraviolet electroluminescence from p-Si/n-ZnO nanorod array heterojunction. J. Vac. Sci. Technol. B 2009, 27, 618-621. [CrossRef]

14. Zhang, Y.; Yao, Y.; Sendeku, M.G.; Yin, L.; Zhan, X.; Wang, F.; Wang, Z.; He, J. Recent progress in CVD growth of 2D transition metal dichalcogenides and related heterostructures. Adv. Mater. 2019, 31, 1901694. [CrossRef]

15. Yang, Z.; Hao, J. Progress in pulsed laser deposited two-dimensional layered materials for device applications. J. Mater. Chem. C 2016, 4, 8859-8878. [CrossRef]

16. Liu, B.; Aydil, E.S. Growth of oriented single-crystalline rutile $\mathrm{TiO}_{2}$ nanorods on transparent conducting substrates for dyesensitized solar cells. J. Am. Chem. Soc. 2009, 131, 3985-3990. [CrossRef]

17. Pawar, S.M.; Pawar, B.S.; Kim, J.H.; Joo, O.S.; Lokhande, C.D. Recent status of chemical bath deposited metal chalcogenide and metal oxide thin films. Curr. Appl. Phys. 2011, 11, 117-161. [CrossRef]

18. Dev, A.; Panda, S.K.; Kar, S.; Chakrabarti, S.; Chaudhuri, S. Surfactant-assisted route to synthesize well-aligned ZnO nanorod arrays on sol-gel-derived ZnO thin films. J. Phys. Chem. B 2006, 110, 14266-14272. [CrossRef] [PubMed]

19. Singh, A.; Singh, A.; Ong, G.K.; Jones, M.R.; Nordlund, D.; Bustillo, K.; Ciston, J.; Alivisatos, A.P.; Milliron, D.J. Dopant mediated assembly of Cu2ZnSnS4 nanorods into atomically coupled 2D sheets in solution. Nano Lett. 2017, 17, 3421-3428. [CrossRef] [PubMed]

20. Harnack, O.; Pacholski, C.; Weller, H.; Yasuda, A.; Wessels, J.M. Rectifying behavior of electrically aligned ZnO nanorods. Nano Lett. 2003, 3, 1097-1101. [CrossRef]

21. Ryan, K.M.; Mastroianni, A.; Stancil, K.A.; Liu, H.; Alivisatos, A.P. Electric-field-assisted assembly of perpendicularly oriented nanorod superlattices. Nano Lett. 2006, 6, 1479-1482. [CrossRef]

22. Pelligra, C.I.; Majewski, P.W.; Osuji, C.O. Large area vertical alignment of ZnO nanowires in semiconducting polymer thin films directed by magnetic fields. Nanoscale 2013, 5, 10511-10517. [CrossRef]

23. Hartmann, L.; Djurado, D.; Florea, I.; Legrand, J.F.; Fiore, A.; Reiss, P.; Doyle, S.; Vorobiev, A.; Pouget, S.; Chandezon, F.; et al. Large-scale simultaneous orientation of CdSe nanorods and regioregular poly(3-hexylthiophene) by mechanical rubbing. Macromolecules 2013, 46, 6177-6186. [CrossRef]

24. Ploshnik, E.; Salant, A.; Banin, U.; Shenhar, R. Hierarchical surface patterns of nanorods obtained by Co-assembly with block copolymers in ultrathin films. Adv. Mater. 2010, 22, 2774-2779. [CrossRef] [PubMed]

25. Thorkelsson, K.; Nelson, J.H.; Alivisatos, A.P.; Xu, T. End-to-end alignment of nanorods in thin films. Nano Lett. 2013, 13, 4908-4913. [CrossRef] [PubMed]

26. Thorkelsson, K.; Mastroianni, A.J.; Ercius, P.; Xu, T. Direct nanorod assembly using block copolymer-based supramolecules. Nano Lett. 2012, 12, 498-504. [CrossRef] 
27. Feng, X.; Sosa-Vargas, L.; Umadevi, S.; Mori, T.; Shimizu, Y.; Hegmann, T. Discotic liquid crystal-functionalized gold nanorods: 2- and 3D self-assembly and macroscopic alignment as well as increased charge carrier mobility in hexagonal columnar liquid crystal hosts affected by molecular packing and $\pi-\pi$ interactions. Adv. Funct. Mater. 2015, 25, 1180-1192. [CrossRef]

28. Nemati, A.; Shadpour, S.; Querciagrossa, L.; Li, L.; Mori, T.; Gao, M.; Zannoni, C.; Hegmann, T. Chirality amplification by desymmetrization of chiral ligand-capped nanoparticles to nanorods quantified in soft condensed matter. Nat. Commun. 2018, 9 3908. [CrossRef]

29. Umadevi, S.; Feng, X.; Hegmann, T. Large area self-assembly of nematic liquid-crystal-functionalized gold nanorods. Adv. Funct. Mater. 2013, 23, 1393-1403. [CrossRef]

30. Kanie, K.; Muramatsu, A. Organic-inorganic hybrid liquid crystals: Thermotropic mesophases formed by hybridization of liquid-crystalline phosphates and monodispersed $\alpha-\mathrm{Fe}_{2} \mathrm{O}_{3}$ particles. J. Am. Chem. Soc. 2005, 127, 11578-11579. [CrossRef]

31. Liu, X.; Qi, G.; Park, A.M.G.; Rodriguez-Gonzalez, A.; Enotiadis, A.; Pan, W.; Kosma, V.; Fuchs, G.D.; Kirby, B.J.; Giannelis, E.P. Scalable synthesis of switchable assemblies of gold nanorod lyotropic liquid crystal nanocomposites. Small 2019, 15, 1901666. [CrossRef] [PubMed]

32. Klöckner, B.; Daniel, P.; Brehmer, M.; Tremel, W.; Zentel, R. Liquid crystalline phases from polymer functionalized ferri-magnetic $\mathrm{Fe}_{3} \mathrm{O}_{4}$ nanorods. J. Mater. Chem. C 2017, 5, 6688-6696. [CrossRef]

33. Zorn, M.; Tahir, M.N.; Bergmann, B.; Tremel, W.; Grigoriadis, C.; Floudas, G.; Zentel, R. Orientation and dynamics of ZnO nanorod liquid crystals in electric fields. Macromol. Rapid Commun. 2010, 31, 1101-1107. [CrossRef] [PubMed]

34. Kubo, S.; Taguchi, R.; Hadano, S.; Narita, M.; Watanabe, O.; Iyoda, T.; Nakagawa, M. Surface-assisted unidirectional orientation of $\mathrm{ZnO}$ nanorods hybridized with nematic liquid crystals. ACS Appl. Mater. Interfaces 2014, 6, 811-818. [CrossRef]

35. Blinov, L.M. Electro-Optical and Magneto-Optical Properties of Liquid Crystals; John Wiley \& Sons Ltd.: New York, NY, USA, 1983; pp. 19-22.

36. Jiang, P.; Bertone, J.F.; Hwang, K.S.; Colvin, V.L. Single-crystal colloidal multilayers of controlled thickness. Chem. Mater. 1999, 11, 2132-2140. [CrossRef] 